\title{
How many metrics are required to identify the effects of the landscape pattern on land surface temperature?
}

\author{
Ailian Chen ${ }^{\mathrm{a}, \mathrm{b}}$, Lei Yao ${ }^{\mathrm{a}, \mathrm{b}}$, Ranhao Sun ${ }^{\mathrm{a}}$, Liding Chen ${ }^{\mathrm{a}, *}$ \\ a State Key Lab of Urban and Regional Ecology, Research Center for Eco-Environmental Sciences, CAS, Beijing 100085, China \\ ${ }^{\mathrm{b}}$ University of Chinese Academy of Sciences, Beijing 100049, China
}

\section{A R T I C L E I N F O}

\section{Article history:}

Received 27 November 2013

Received in revised form 7 April 2014

Accepted 12 May 2014

\section{Keywords:}

Beijing

Landscape metrics

LST

Surface urban heat island

UHI

\begin{abstract}
A B S T R A C T
Urban heat island (UHI) is a global issue as a result of urbanization. Land surface temperature (LST) is closely related to the thermal environment and energy budget of the earth surface, and is an important parameter in identifying UHI effects. Previous studies have proved the effects of landscape pattern on LST by using landscape metrics. However, the metrics used were inconsistent in number and type. Further, fewer studies tried to select representative metrics from the numerous metrics for LST indication. In this study we tried to explore the effects of landscape pattern on LST in Beijing by using the representative class level metrics selected through cluster analysis, factor analysis and regression. The results showed a composition metric such as PLAND (e.g. percentage of impervious surface in a landscape) alone explained about 56\% of the landscape mean LST, whereas adding a configuration metric such as LSI (landscape shape index) or Gyrate_MN (mean gyration index) explained approximate another 6-12\%. Adding more other configuration metrics does not improve the regression model performance more than $1 \%$. The regression results also revealed that without targeted dependent variables, the factor analysis is of no use for choosing landscape metrics. These indicate that landscape composition and configuration both have effects on landscape mean LST, while composition is much more important than configuration, and that a combination of one composition metric with no more than four configuration metrics of impervious surface is sufficient for LST prediction. These results can help landscape ecologists in using landscape metrics and further help landscape planners to balance land cover in urban planning.
\end{abstract}

(c) 2014 Elsevier Ltd. All rights reserved.

\section{Introduction}

The urban heat island (UHI) is a global phenomenon that affects air quality (Sarrat et al., 2006), water use, energy consumption, human health, and urban sustainability (Frumkin and McMichael, 2008; Gober et al., 2010; Grimm et al., 2008). It is important to realize that there are primarily two types of UHI: air UHI and surface UHI. Air UHI refers to the phenomenon whereby air temperature in urban areas is higher than in the surrounding suburban areas. Surface UHI refers to the difference in the land surface temperature (LST) between urban and less urbanized areas. The LST is the skin temperature of an area that is determined by air temperature and long-wave radiation between the surface and the atmosphere (Weng, 2009). Unlike air temperature, LST has higher spatially continuous coverage and has frequently been used to assess UHIs in

\footnotetext{
* Corresponding author. Tel.: +86 101062943840.

E-mail address: liding@rcees.ac.cn (L. Chen).
}

recent decades (Voogt, 2002; Buyantuyev and Wu, 2010; Liu and Weng, 2008, 2009; Schwarz et al., 2011).

A large body of research has tried to identify surface UHI or the associated LST using landscape metrics (Connors et al., 2013; Li et al., 2011; Zhou et al., 2011). Landscape metrics as descriptions of landscape patterns are believed to have relationship with climate (Stone, 2009). Numerous indices have been proposed to measure landscape patterns (Baker and Cai, 1992; McGarigal et al., 2012; Riitters et al., 1995), including the composition and configuration characteristics of land use/cover. Of these indices, the landscape metrics advanced by McGarigal et al. (2012) are the most widely used measures (Kupfer, 2012; Uuemaa et al., 2013). The software FRAGSTATS developed by McGarigal et al. (2012) has became widely used for calculating landscape metrics in many fields, ranging from evaluating land use/cover changes to analyze the effects of landscape pattern on different kinds of ecosystem services (Uuemaa et al., 2013). However, the number of landscape metrics used in previous studies has ranged from 2 to more than 10 (Cao et al., 2010; Connors et al., 2013; Li et al., 2012, 2013; Sun et al., 2012; Weng et al., 2007). Frequently used metrics have 
included: percentage of landscape (PLAND), mean patch size (MPS), perimeter-area fractal dimension (PAFRAC), aggregation index (AI), cohesion index (COHESION), contagion index (CONTAG), and Shannon's diversity index (SHDI).

Yet less attention has been paid to the selection of landscape metrics either targeted to LST/UHI studies or to other environmental processes. In general, the metrics in common use have been selected on the basis of the results of Riitters et al. (1995). Riitters et al. (1995) carried out a factor analysis on landscape pattern indices to reduce the metrics dimension, but not to analyze urban heat islands. In some cases, all of the metrics have been used (Schindler et al., 2013). Uuemaa et al. (2013) reviewed the trend of using landscape metrics as indicators for ecological processes and found that climate/microclimate regulation had received limited attention. As landscape metrics provided a comprehensive description of the proportion, shape and spatial arrangements of different land cover, a selection based on targeted statistics would thus be necessary and helpful for metrics selection and urban planning. In addition, little is known about the role of configuration in affecting LST. Hence, it is necessary to conduct further test studies on the effects of landscape patterns on LST using landscape metrics.

This study focused on finding appropriate metrics that can effectively identify the effects of landscape patterns on urban heat islands. The objectives of this study were: (1) to explore the role of landscape composition and configuration in indicating UHIassociated LST for a metropolis; and (2) to select the most frugal and effective metrics for LST indication.

\section{Methodology}

\subsection{Study area and materials}

\subsubsection{Study area}

The city of Beijing, China was selected as the study area. The city spreads out in five concentric ring roads, from the Second to the Sixth Ring Road. The Second Ring Road follows the old city walls and the Sixth Ring Road connects satellite towns in the surrounding suburbs. The city has a monsoon-influenced humid continental climate characterized by hot-humid summers and cold-windy-dry winters. The average daytime high temperature in January (usually the coldest month) is around $1^{\circ} \mathrm{C}$, whereas that in July (usually the hottest month) is above $30^{\circ} \mathrm{C}$. Both air UHI and surface UHI of Beijing have been investigated and have shown a trend of incensement with enhancing urbanization (Miao et al., 2009; Ji et al., 2006). Though average summer daytime air UHI intensity (temperature difference) in the 1970 s was only about $1{ }^{\circ} \mathrm{C}$ and had kept increasing by merely $0.31^{\circ} \mathrm{C}$ every 10 years since (Yu et al., 2005), surface UHI analysis have showed higher UHI intensity, ranging from 5 to more than $10^{\circ} \mathrm{C}$ (Wang et al., 2007).

In this study, the region inside the Fifth Ring Road, as shown in Fig. 1, was used for study because this is the main metropolitan area. The study region ranges south to north from $39.75^{\circ} \mathrm{N}$ to $40.0^{\circ} \mathrm{N}$ and west to east from $116.25^{\circ} \mathrm{E}$ to $116.5^{\circ} \mathrm{E}$, and takes up an area of $667 \mathrm{~km}^{2}$. This region, which has an elevation of 40-60 m, occupies a relatively small but expanding proportion of the municipality's total area (about $16800 \mathrm{~km}^{2}$ ).

\subsubsection{Materials}

2.1.2.1. Land cover map. Six swaths of QuickBird (QB) images were used to obtain land cover data. The central parts of the study area ( $\sim 75 \%$ ) were covered by two QB images taken on July 5, 2002, and the other parts were covered by four QB images. The two eastern images were taken on April 24, 2002 and the two western images were taken on April 1, 2002.
Four types of land cover were firstly considered for land use classification: vegetation, water, bare soil and built up areas or impervious surface (IS). The vegetation in the metropolis was mainly a mix of grass, shrubs, and trees. IS included buildings and impervious roads. Bare soil was generally bare land that was intended to be built upon. "Water" refers to rivers and lakes.

Unsupervised classification and the Decision Tree method in the $\mathrm{ENVI}^{\mathrm{TM}}$ (Version 5.0) software were combined to obtain the land cover data by the following three steps.

First, 12 classes, a maximum of 15 interactions and the K-means method were set to do the unsupervised classification based on the reflectance of four multi-spectral bands of $\mathrm{QB}$ images. The resulting 12 classes were checked manually to determine a class attribute, i.e. trees, shrubs, grass, crops, agricultural greenhouses, water, shadow, wet bare soil, dry bare soil, bright IS, medium bright IS, and dark IS. These classes were checked to ensure precise classification using sample regions, selected with the aid of the pan band images. Similar classes such as all the vegetations are combined. The mixed classes occurred between water, shadow and dark IS, and between wet bare soil and medium bright IS.

Second, the remaining mistaken classes were discriminated by the normalized difference vegetation index (NDVI) and an index that we constructed: the water-shadow distinction index (WSDI). The NDVI was used to discriminate wet bare soil from medium bright IS, and also to ensure the distinction between vegetation, water, and IS. The WSDI was used to discriminate water and shadow from dark IS. Wet bare soil mostly consisted of the croplands that had been irrigated, and had an NDVI value similar to vegetation but higher than IS.

The NDVI was calculated by Eq. (1):

$\mathrm{NDVI}=\frac{\rho(\text { Band } 4)-\rho(\text { Band } 3)}{\rho(\text { Band } 4)+\rho(\text { Band } 3)}$,

where $\rho$ (Band 4) and $\rho$ (Band 3) represent top-of-atmosphere (TOA) reflectance transformed from the digital value (DN) of $\mathrm{QB}$ Bands 4 and 3, respectively. TOA reflectance is the at-sensor reflectance with the cosine effect of the solar zenith and the exoatmospheric solar irradiance due to variation in the sun-earth distance removed (Chander and Groeneveld, 2009; Li et al., 2011).

The WSDI was built according to the spectrum profiles of dark IS, shadow, and water. Their spectrum was similar to each other in the slope between Band 2 and Band 3, whereas the profiles of water were steeper between Band 3 and Band 4 than that of dark IS and shadow (See Appendix for detailed spectrum profiles).

Therefore, the WSDI was calculated with the following equation:

WSDI $=\frac{\rho(\text { Band } 4)-\rho(\text { Band } 3)}{\rho(\text { Band } 2)-\rho(\text { Band } 3)}$,

similar as in Eq. (1), $\rho$ (Band 2) represents TOA reflectance of $\mathrm{QB}$ Band 2. In our study, water often had a mean WSDI less than 0.5, whereas dark IS and shadow had mean WSDIs higher than 0.5 but less than 1 . The areas of shadow were mainly built-up roads shaded by nearby buildings. Shadow and built-up roads were therefore also combined as a single type. Each image has a slightly different WSDI because of environmental effects such as the acquisition date and the atmosphere. Basic statistic analysis of NDVI and WSDI of each image was conducted to decide the thresholds for the building of the decision trees.

Finally a 3 by 3 window was used to clump the classification results. This eliminated very small pieces of pixels within a patch. The overall precision was $85.2 \%$ (31674/37174 pixels), and the Kappa coefficient was 0.79 . The land cover mapping resulted in a pattern of land cover with 931.0 ha (1.4\%) of water, 26882.5 ha (40.3\%) of vegetation, 38915.3 ha of impervious surface $(50.3 \%)$ and 5320.0 ha $(8.0 \%)$ of bare soil, as shown in Fig. 1. 

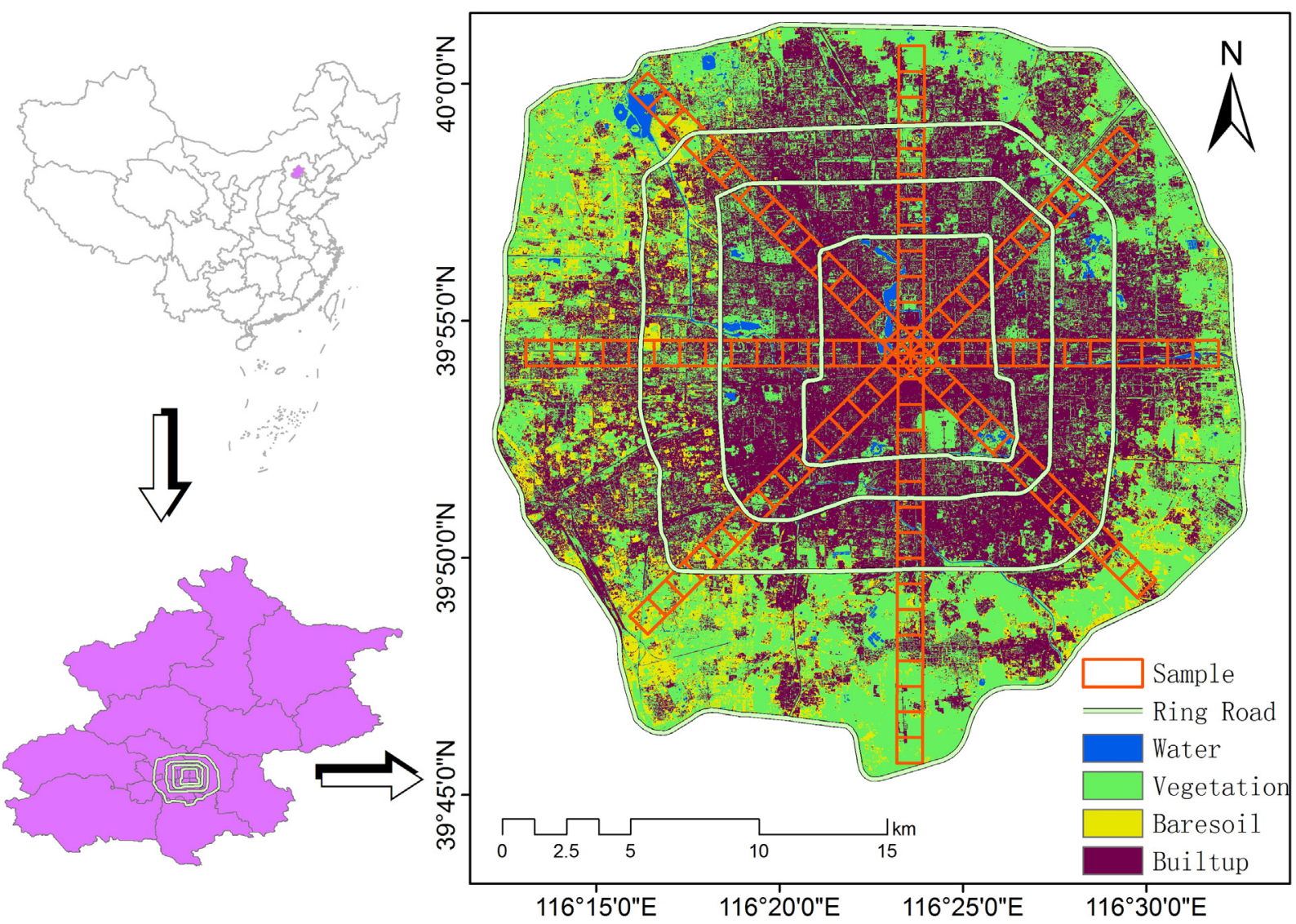

Fig. 1. Land cover, the samples used for research and location of the study area.

2.1.2.2. Land surface temperature. A swath of cloud-free Landsat ETM+ image, acquired on July 9, 2002, was selected to retrieve the LST. One swath of ETM+ image covers the whole study area. The $\mathrm{ETM}+$ image was geometrically rectified and registered to the same projection system (datum: WGS 84, UTM Zone North 50) as all the QuickBird images in the ENVI ${ }^{\mathrm{TM}}$ software. Band 6 of the ETM+ data was resampled to a resolution of $30 \mathrm{~m}$ as Bands 3 and 4, and was used to retrieve the LST.

The LST was retrieved from the thermal Band of ETM+ image based on Planck's law (Eq. (3)). LST data were obtained by three steps (Jiménez-Muñoz and Sobrino, 2003): (1) the image digital number was converted back to at-sensor radiance with the scaling parameters provided along with the image metafile (NASA, 2000), (2) at-sensor radiance was converted to at-sensor temperature according to Eqs. (3) and (4), and (3) the at-sensor temperature was adjusted to LST with land surface emissivity $(\varepsilon)$ (Eq. (5)).

Planck's law is shown in Eq. (3):

$M_{\lambda}(T)=\frac{2 \pi h c^{2} \lambda^{-5}}{e^{(h c / \lambda k T)}-1}$.

In our retrieval, $M_{\lambda}(T)$ is the at-sensor radiance; $h$ is the Planck constant, which equals $6.626 \times 10^{-34} \mathrm{Js} ; K$ is the Boltzmann constant, which equals $1.3806 \times 10^{-23} \mathrm{JK}^{-1} ; c$ is the velocity of light, which is $2.998 \times 10^{8} \mathrm{~m} \mathrm{~s}^{-1}$; and $T$ (unit, $\mathrm{K}$ ) is the Kelvin temperature. With these constants, $T$ can be retrieved by Eq. (4):

$T=\frac{1282.71}{\ln \left(666.09 / M_{\lambda}(T)+1\right)}$.
This at-sensor temperature was corrected to LST with land surface emissivity by Eq. (5):

$\mathrm{LST}=\frac{1282.71}{\ln \left(666.09 /\left(\varepsilon M_{\lambda}(T)\right)+1\right)}$,

where $\varepsilon$ is land surface emissivity estimated by NDVI according to the method used by Sobrino et al. (2004). We neglected the role of atmospheric effects in relation to the retrieval result for four reasons: (1) atmospheric corrections based on an image or model with general parameters resulted in little error for the LST retrieval (Sobrino et al., 2004); (2) the images were cloudfree; and (3) most importantly, the focus in our study was on the correlation coefficients but was not based on the absolute LST value itself. Thus, the atmospheric effects on LST throughout a single image were considered to be consistent and were therefore negligible.

The resulting LST in units Kelvin (K) was finally converted to Celsius $\left({ }^{\circ} \mathrm{C}\right)$ and mapped as Fig. 2.

More than 20 regions of interest (ROIs) of different land cover classes were selected to summarize the basic statistics of LST, as shown in Table 1. Impervious surface had the highest mean LST, whereas water had the lowest.

Table 1

Basic statistics of land surface temperature (LST) for four land-cover classes.

\begin{tabular}{llll}
\hline Land cover class & \multicolumn{2}{l}{ LST $\left({ }^{\circ} \mathrm{C}\right)$} & \\
\cline { 2 - 4 } & Min & Mean & Max \\
\hline Bare soil & 23.78 & 28.98 & 33.20 \\
Impervious & 25.22 & 29.80 & 35.59 \\
Water & 22.77 & 24.93 & 30.26 \\
Vegetation & 22.77 & 26.69 & 32.71 \\
\hline
\end{tabular}




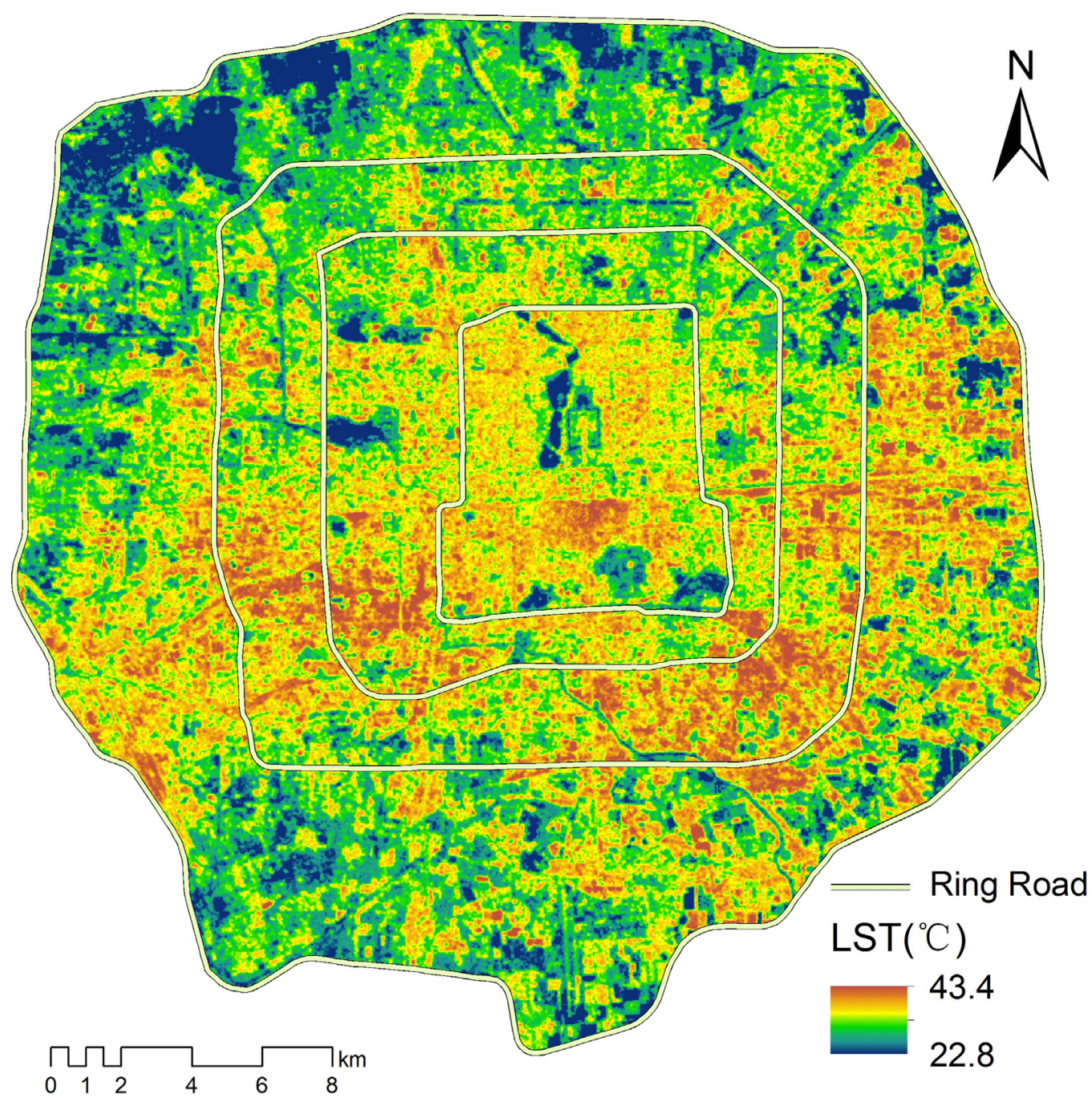

Fig. 2. Distribution of land surface temperature on July 9, 2002.

2.1.2.3. Landscape metrics. Sample landscapes were created by transects. Four transects were built with each crossing the city center area (Fig. 1). In total, 106 grids were created along four transects in $1 \mathrm{~km} \times 1 \mathrm{~km}$ grids. As with many forest loss studies, the scales of $10 \mathrm{~s}$ to $1000 \mathrm{~s}$ of $\mathrm{km}^{2}$ may be of the greatest interest to management (Forman and Godron, 1986; Kupfer, 2012). However, for urban studies, the micro-scale between $10 \mathrm{~s}$ and $1000 \mathrm{~s} \mathrm{~m}^{2}$ is of greater relevance for the microclimate (Connors et al., 2013). We therefore used the $1 \mathrm{~km} \times 1 \mathrm{~km}$ grids as sample regions because this size was more convenient and also covered the micro-scale.

There are three levels of landscape metrics in FRAGSTATS: patch level, class level, and landscape level. Only the metrics at class level were calculated in this study. This is because that a landscape often contains different land cover classes that function conversely to LST. For instance, vegetation helps to cool down the mean LST, whereas impervious areas raise the mean LST. Landscape level metrics rely on an average value of different classes that function conversely to LST, and patch level metrics are average values of patches of all classes (Detailed for the calculation of metrics can be found in McGarigal et al. (2012). They were not counted as they made no sense in predicting LST and their relation with LST was difficult to interpret.
As bare soil was rare in the study regions and it had high LST similar to impervious surface (Table 1), we combined it to the class of impervious surface. We together counted metrics of three classes: vegetation, water, and impervious surface.

There are seven categories of metrics at class level (Table 2), including: (1) area/density/edge, (2) shape, (3) core area, (4) isolation/proximity, (5) contrast, (6) contagion/interspersion, and (7) connectivity. For each category, there are several metrics. The counted metrics are shown in Table 2.

All of the metrics in Table 2, except for the category of "contrast," were calculated. The contrast metrics were not used in this study was because there was no reference available for the definition of "edge contrast" (which is needed for calculating contrast metrics) to relate to LST. Core area metrics also required a parameter called the "edge depth." We used $30 \mathrm{~m}$ as an edge depth because the resolution of LST is $30 \mathrm{~m}$. The land cover on the $30 \mathrm{~m}$ edge may affect the LST. Isolation/proximity requires a searching radius and we appointed $100 \mathrm{~m}$ as a simple example of micro-scale (Connors et al., 2013). Detailed information for these metrics can be found in the study by McGarigal et al. (2012).

We calculated 45 metrics, of which 32 metrics were retained to promise the variables to samples ratio at about $1: 3$, as shown in Fig. 3. The other 13 metrics were excluded because they either have 


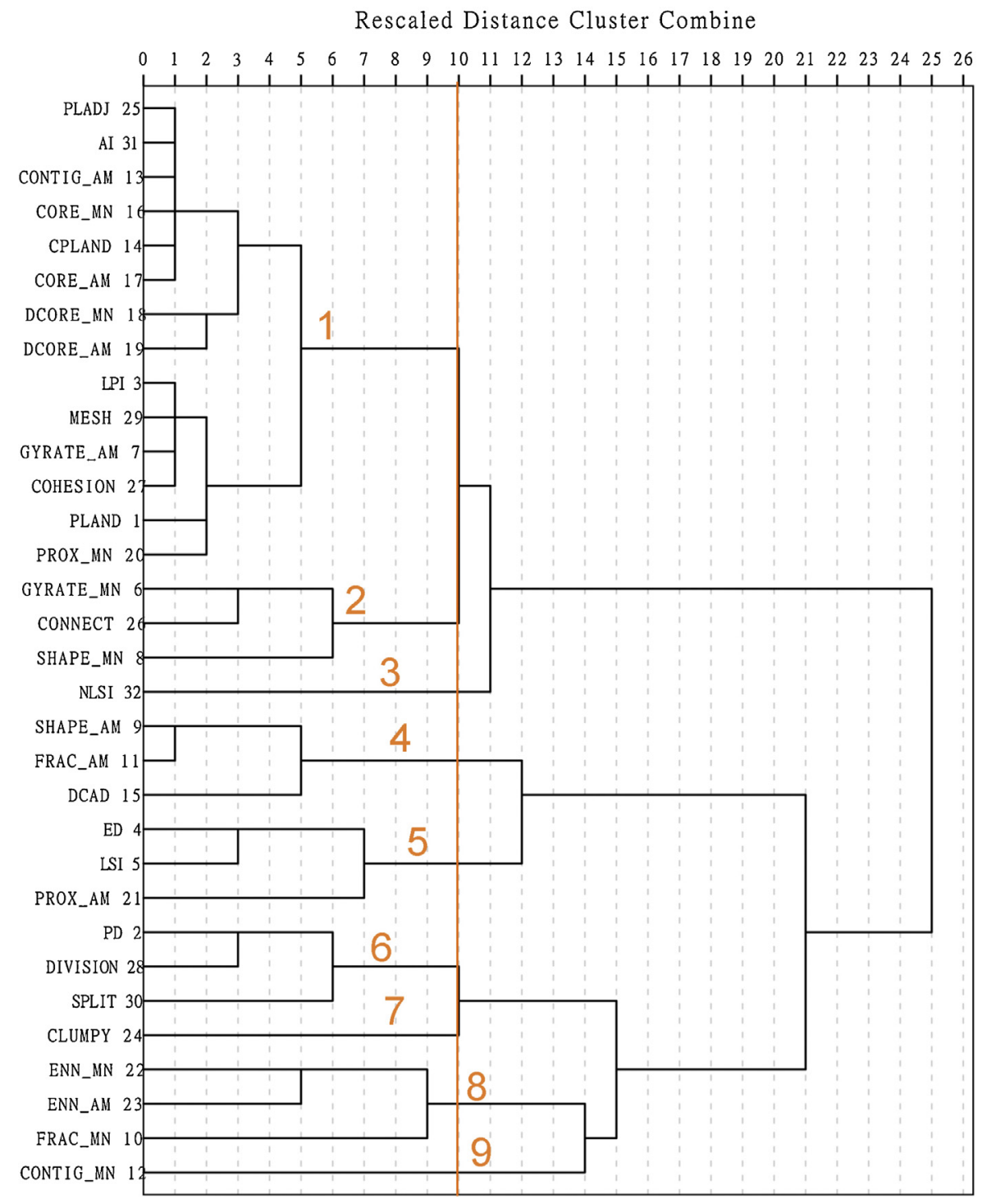

Fig. 3. Dendrogram of cluster analysis using average linkage between groups of Pearson correlation.

invalid value or totally redundant to each other. Namely, Metrics with Pearson correlation coefficients to each other approximating 1 were deleted. For instance, TE (total edge) and ED (edge density) were totally redundant as ED equals to TE dividing by the analyzing landscape area, which in our study was $1 \mathrm{~km} \times 1 \mathrm{~km}$. The Interspersion Juxtaposition Index (IJI) in the category of contagion/interspersion for many grids was invalid and excluded because the "water" class was rare, and IJI was only countable when there were three classes in a grid.

\subsubsection{Statistical analysis}

We first transformed all of the metrics with a natural logarithm, because the magnitude of some metrics can be from tens to thousands and some metrics have no dimension. As the number of sample grids that had water class was less than 20 , majority with no more than $1 \%$ of water, water metrics were not considered for further analysis. The metrics of vegetation and impervious surface were first checked for co-linearity correlation, and obvious redundancy. Metrics with Pearson correlation coefficients equals to 1 to each other were deleted. The metrics referred herein after meant the natural logarithm transformed values of the metrics, except for otherwise indicated.

We then used cluster analysis, primary component analysis (PCA), and linear regressions to select representative metrics for LST indication. Cluster analysis of the variables (i.e. the metrics in our study) grouped the metrics that were more related and therefore we could reduce similar metrics before PCA to eliminate inherent redundancy. PCA grouped metrics again and resulted in primary factors or primary components (PCs). PCA was conducted on the remaining metrics after selection by the cluster analysis, and the PCs were recorded as variables. This was because there might have been correlation and hidden redundancy within all the metrics counted, and the resulting PCs might still have been redundant. Therefore, metrics belonging to the same cluster and having similar meanings (i.e. belonging to same categories as shown in Table 2) were excluded before the PCA.

Linear regression was further performed between the metrics and the mean LST of each sample grid to identify the explanation of the metrics relevant to the LST. Regressions were conducted in two categories regarding the input independent variables. The first category simply inputted all independent variables by the 
Table 2

All 45 class-level metrics counted for the sample data (for a detailed definition, see McGarigal et al., 2012).

\begin{tabular}{|c|c|}
\hline Category (number of counted metrics) & Metrics \\
\hline Area/density/edge (11) & $\begin{array}{l}\text { Class area - CA, percentage of } \\
\text { landscape - PLAND, patch density } \\
\text { - PD, number of patches - NP, large } \\
\text { patch index - LPI, landscape shape } \\
\text { index - LSI, normalized landscape } \\
\text { shape index - NLSI, total edge - TE, } \\
\text { edge density - ED, mean gyration } \\
\text { index - GYRATE_MN, } \\
\text { area-weighted gyration index - } \\
\text { GYRATE_AM }\end{array}$ \\
\hline Shape (11) & $\begin{array}{l}\text { Mean perimeter area ratio - } \\
\text { PARA_MN, area-weighted } \\
\text { perimeter area ratio - PARA_AM, } \\
\text { perimeter-area fractal dimension - } \\
\text { PAFRAC, area-weighted related } \\
\text { circumscribing circle - CIRCLE_AM, } \\
\text { mean related circumscribing circle } \\
\text { - CIRCLE_MN, mean shape index - } \\
\text { SHAPE_MN, area-weighted shape } \\
\text { index - SHAPE_AM, mean fractal } \\
\text { dimension index - FRAC_MN, } \\
\text { area-weighted fractal dimension } \\
\text { index - FRAC_AM, mean contiguity } \\
\text { index - CONTIG_MN, } \\
\text { area-weighted contiguity index - } \\
\text { CONTIG_AM }\end{array}$ \\
\hline Core area (8) & $\begin{array}{l}\text { Total core area - TCA, core area } \\
\text { percent of landscape - CPLAND, } \\
\text { number of disjunct core areas - } \\
\text { NDCA, disjunct core area density - } \\
\text { DCAD, mean core area - CORE_MN, } \\
\text { area-weighted core area - } \\
\text { CORE_AM, mean disjunct core area } \\
\text { - DCORE_MN, area-weighted - } \\
\text { DCORE_AM }\end{array}$ \\
\hline Isolation/proximity (6) & $\begin{array}{l}\text { Mean proximity index - PROX_MN, } \\
\text { area-weighted proximity index - } \\
\text { PROX_AM, mean similarity index - } \\
\text { SIMI_MN, area-weighted similarity } \\
\text { index - SIMI_AM, mean Euclidean } \\
\text { nearest neighbor distance - } \\
\text { ENN_MN, area-weighted Euclidean } \\
\text { nearest neighbor distance - } \\
\text { ENN_AM }\end{array}$ \\
\hline \multicolumn{2}{|l|}{ Contrast (0) } \\
\hline Contagion/interspersion (7) & $\begin{array}{l}\text { Clumpiness index - CLUMPY, } \\
\text { percentage of like adjacencies - } \\
\text { PLADJ, aggregation index - AI, } \\
\text { interspersion and juxtaposition } \\
\text { index - IJI, division index - } \\
\text { DIVISION, effective mesh size - } \\
\text { MESH, splitting index - SPLIT }\end{array}$ \\
\hline Connectivity (2) & $\begin{array}{l}\text { Patch cohesion index - COHESION, } \\
\text { connectance - CONNECT }\end{array}$ \\
\hline
\end{tabular}

"enter" method, and the second category used a stepwise method. Each category had five scenarios based on input variables, namely: (1) all metrics before cluster analysis, (2) the metrics selected after cluster analysis, (3) all metrics selected after PCA (heavily loaded on primary components), (4) all the metrics excluded after cluster analysis and all primary components (PCs), and (5) all PCs.

In addition to these scenarios, easily implemented metrics such as mean shape (SHAPE_MN) and representative metrics resulting from the stepwise regression (such as LSI) were also regressed alone or combined to check their performances. The criteria for the stepwise regression were: probability-of-F-to-enter $\leq 0.05$ and probability-of- $F$-to-remove $\geq 0.10$. All statistical analysis was conducted by SPSS $^{\mathrm{TM}}$ (version 18 ).

\section{Results}

\subsection{Clusters and primary components of metrics}

The results of the cluster analysis are shown in Fig. 3. "Cluster combine rescaled distances" equaling to 10 was considered suitable to group the metrics and nine clusters were resulted, with each clusters representing a different aspect or categories of the pattern metrics. The first cluster may be termed as composition, composition-weighted configuration (such as CONTIG_AM, DCORE_AM), and large patch dominance (Cain et al., 1997; Cushman et al., 2008). The second, third, and forth clusters (such as GYRATE_MN, CONNECT and SHAPE_AM) is related to shape or the average perimeter characteristics. The fifth and sixth clusters are the edge density (ED) or division index (DIVIVISION), which are also related to the perimeter. The left three clusters are the combination of shape and proximity, which can be termed as adjacency.

Twenty-two metrics remained for factor analysis (Table 3). Ten metrics, including CPLAND, CONTIG_MN, FRAC_AM, ENN_AM, DCORE_AM, GYRATE_MN, GYRATE_AM, CORE_AM, PLADJ, and SHAPE_AM were excluded. Four primary components (PCs) resulted from the PCA with the threshold of an eigenvalue larger than 1. Four PCs together explained about $89 \%$ of the variation in all 22 metrics. The first PC mainly correlated to composition/area metrics (e.g. PLAND, LPI) and contagion metrics (MESH, SPLIT). The second PC was correlated to edge metrics (ED, LSI), the third was correlated to the combination of the first and the second PCs, and the final PC was simply shape metrics (e.g. FRAC_MN and SHAPE_MN).

\subsection{Metrics as predictors for LST in regression models}

The results of the simple "enter" regression are shown in Table 4. Akeike information criterion (AIC), $R$ square $\left(R^{2}\right)$ and adjusted $R^{2}$ indicating fitting robustness and the determination coefficients are given in the table. All 32 metrics before cluster analysis (Model 1) and the 22 metrics selected after cluster analysis (Model 2) explained almost the same variation in LST. The metrics selected after clustering provided a better-fitting model, namely, Model 2, with adjusted $R^{2}$ equaling to 0.696 versus Model 1 with an adjusted $R^{2}$ of 0.688 . All of the metrics excluded after the clusters and the four PCs (Model 3) explained slightly less variation in LST than all metrics selected before or after clustering (Models 1 and 2), so as all the PCs (Models 4) and the metrics heavily loaded on PCs did (Model 5). However, AIC (smaller AIC indicates the better model fitting) showed that the least input variables (Model 5) resulted in the best models.

The values of standardized regression coefficient (beta, $\beta$ ) and the determination coefficient of each stepwise regression model are shown in Table 5. All of the models have a similar $R^{2}$ (between 0.671 and 0.684 ). PLAND was selected by the best-fit model if it was present in the input independent variables (Models 6, $7,9)$. Otherwise, the variables that represented the meaning of PLAND, such as CORE_MN, or PC1 were selected and played the most important role (highest $\beta$ ) in relation to LST in the best models (Models 8 and 10). The landscape shape index (LSI) and the percentage of like adjacencies (PLADJ) and PC3 (PC3 represents NLSI and CLUMPY, as shown in Table 3 ) as a configuration index was also selected by the best-fit model (Models 8 and 9).

The results of fitting selected metrics to the mean LST are shown in Table 6. A combination of PLAND and a shape or edge metric explained almost the same amount variation in LST (e.g. Models $12,14,16,17$, and 18). CORE_MN alone (Model 15) explained 
Table 3

Rotated components matrix and initial eigenvalue, rotated cumulative (cum.) variance explained for the spatial pattern of impervious surface.

\begin{tabular}{|c|c|c|c|c|}
\hline \multirow[t]{2}{*}{ Initial eigenvalue/rotated cum. variance explained/metrics } & \multicolumn{4}{|c|}{ Primary component $(\mathrm{PC})$} \\
\hline & PC 1 & PC 2 & PC 3 & PC 4 \\
\hline Initial eigenvalue & 11.745 & 4.224 & 2.035 & 1.527 \\
\hline Rotated cum. variance explained & 37.867 & 64.531 & 78.8792 & 88.779 \\
\hline COHESION & 0.947 & -0.133 & 0.118 & \\
\hline MESH & 0.938 & -0.194 & 0.236 & -0.105 \\
\hline SPLIT & -0.938 & 0.194 & -0.236 & 0.105 \\
\hline LPI & 0.931 & -0.191 & 0.216 & -0.110 \\
\hline PLAND & 0.918 & & 0.291 & \\
\hline PROX_MN & 0.864 & -0.108 & 0.270 & -0.348 \\
\hline AI & 0.763 & -0.621 & & \\
\hline CORE_MN & 0.722 & -0.647 & 0.191 & \\
\hline DCAD & 0.608 & 0.555 & 0.343 & \\
\hline ENN_MN & -0.528 & -0.132 & -0.414 & 0.472 \\
\hline ED & 0.165 & 0.956 & 0.128 & \\
\hline LSI & -0.319 & 0.930 & & \\
\hline DCORE_MN & & 0.766 & -0.359 & -0.166 \\
\hline PROX_AM & 0.523 & -0.764 & -0.163 & \\
\hline PD & -0.471 & 0.737 & -0.394 & -0.170 \\
\hline CONNECT & 0.497 & -0.692 & 0.354 & 0.232 \\
\hline DIVISION & -0.531 & 0.604 & -0.550 & 0.143 \\
\hline CLUMPY & -0.304 & & -0.905 & 0.109 \\
\hline NLSI & 0.334 & -0.188 & 0.868 & -0.150 \\
\hline FRAC_MN & -0.247 & & -0.104 & 0.859 \\
\hline SHAPE_MN & 0.200 & -0.328 & 0.487 & 0.729 \\
\hline CONTIG_MN & & & -0.141 & 0.578 \\
\hline
\end{tabular}

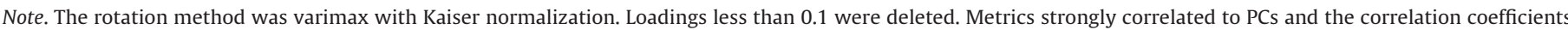
are marked in bold.

Table 4

The determinative coefficient $\left(R^{2}\right)$ for linear regression between LST and metrics and primary components (PCs) as different scenarios of input variables.

\begin{tabular}{|c|c|c|c|c|}
\hline Model & Independent variables & Number of variables & (Adjusted $R^{2}$ ) $R^{2}$ & AIC \\
\hline $1^{* *}$ & All metrics before clustering & 32 & $(0.688) 0.770$ & -114.20 \\
\hline $2^{* *}$ & All metrics selected after clustering & 22 & $(0.696) 0.753$ & -126.71 \\
\hline $3^{* *}$ & Four PCs and the 10 metrics excluded after clustering & 14 & $(0.665) 0.707$ & -124.34 \\
\hline $4^{* *}$ & All metrics heavily loaded on four PCs & 13 & $(0.645) 0.686$ & -119.01 \\
\hline $5^{* *}$ & All PCs & 4 & $(0.663) 0.676$ & -133.78 \\
\hline
\end{tabular}

Note. The number of cases is 106 . AIC is Akeike information criterion. Models with highest adjusted $\mathrm{R}^{2}$ are marked in bold.

Significance is at the 0.01 level (two-tailed).

Table 5

Determination coefficients $\left(R^{2}\right)$ and selected independent variables in the best-fit models during stepwise regression.

\begin{tabular}{|c|c|c|c|c|}
\hline Best-fit model & Independent variables & (Adjusted $R^{2}$ ) $R^{2}$ & $\begin{array}{l}\text { Selected variables } \\
\text { (Beta) }\end{array}$ & AIC \\
\hline 6 & All metrics before cluster & $(0.678) 0.684$ & $\begin{array}{l}\text { CORE_MN }(0.044)^{* *} \\
\text { PLAND }(\mathbf{0 . 2 1 5})^{* *}\end{array}$ & -140.49 \\
\hline 7 & All metrics selected after clusters & $(0.678) 0.684$ & $\begin{array}{l}\text { CORE_MN }(0.044)^{* *} \\
\text { PLAND }(\mathbf{0 . 2 1 5})^{* *}\end{array}$ & -136.24 \\
\hline 8 & $\begin{array}{l}\text { Four primary components and the } 10 \\
\text { metrics excluded after clustering }\end{array}$ & $(0.661) 0.671$ & $\begin{array}{l}\text { PLADJ }(0.358)^{* *} \\
\text { PC3 }(0.216)^{* *} \\
\text { CORE_MN }(\mathbf{0 . 4 2 5})^{*}\end{array}$ & -107.41 \\
\hline 9 & All metrics heavily loaded on four PCS & $(0.665) 0.671$ & $\begin{array}{l}\text { LSI }(-0.361)^{* *} \\
\text { PLAND }(\mathbf{0 . 6 0 6})^{* *}\end{array}$ & -131.16 \\
\hline 10 & Four primary components & $(0.666) 0.676$ & $\begin{array}{l}\text { PC1 }(\mathbf{0 . 6 6 4}) \\
\text { PC2 }(-\mathbf{0 . 4 0 0})^{* *} \\
\text { PC3 }(0.274)^{* *}\end{array}$ & -135.78 \\
\hline
\end{tabular}

Note. PCs is short for primary components. AIC is Akeike information criterion. Metrics with higher standardized coefficients (Beta) are marked in bold.

* The coefficient was significant at the 0.05 level (two-tailed).

** The coefficient was significant at the 0.01 level (two-tailed).

approximately the same amount of LST as the combination of PLAND and the shape/edge metrics (Models 12,14,16,17, and 18). CORE_MN alone (Model 15) was better than PLAND alone (Model 16). The combination of PLAND and SHAPE_MN (Model 13) performed slightly worse than a combination of PLAND with other shape or edge metrics (Models 12 and 14).

\section{Discussion}

It is critical to reduce the numbers of landscape metrics and select several useful and representative metrics to indicate the targeted dependent variables. In our study, we have targeted our analysis of metrics at the LST, which provides insights both to use 
Table 6

Determinative coefficient $\left(R^{2}\right)$ for linear regression between metrics and LST.

\begin{tabular}{|c|c|c|c|}
\hline Model & Input variables (unstandardized coefficients) & $\left(\right.$ Adjusted $\left.R^{2}\right) R^{2}$ & AIC \\
\hline 11 & $\operatorname{PLAND}\left(1.816^{* *}\right)$ & $(0.560) 0.564$ & -107.41 \\
\hline 12 & $\operatorname{PLAND}\left(1.469^{* *}\right), \operatorname{LSI}\left(-1.058^{* *}\right)$ & $(0.668) 0.674$ & -136.14 \\
\hline 13 & PLAND $\left(1.754^{* *}\right)$, SHAPE_MN $\left(0.396^{* *}\right)$ & $(0.564) 0.573$ & -107.45 \\
\hline 14 & PLAND $\left(1.470^{* *}\right)$, GYRATE_MN $\left(0.501^{* *}\right)$ & $(0.626) 0.633$ & -123.84 \\
\hline 15 & CORE_MN $\left(0.394^{* *}\right)$ & $(0.643) 0.647$ & -139.66 \\
\hline 16 & CORE_MN $\left(0.466^{* *}\right)$, LSI $\left(0.523^{* *}\right)$ & $(0.678) 0.687$ & -129.58 \\
\hline 17 & CORE_MN $\left(0.429^{* *}\right)$, SHAPE_MN $\left(-0.590^{* *}\right)$ & $(0.655) 0.662$ & -130.73 \\
\hline 18 & CORE_MN $\left(0.447^{* *}\right)$, GYRATE_MN $\left(-0.225^{* *}\right)$ & $(0.647) 0.653$ & -132.17 \\
\hline
\end{tabular}

Note. AIC is Akeike information criterion.

${ }^{* *}$ Coefficient is at the 0.01 level (two-tailed).

the metrics for landscape ecologists and to indicate UHI for urban planners.

\subsection{Clusters and primary components of the metrics}

The clusters and PCs of the metrics in a metropolis can be represented by two groups: the composition metrics and the edge or edge-related metrics. The metrics in cluster 1 are closely correlated with each other because they are metrics concerning area/composition or the area-weighted configuration (and they could in fact be combined to composition.) The other clusters, from the second to the ninth clusters, were mainly metrics relating to average shape or edge.

The results of the PCA are similar to the results of the cluster analysis. The metrics heavily loaded on the first factor are mainly correlated with composition or large patch characteristics. The other factors are highly correlated to average shape such as LSI, SHAPE_MN, and proximity, which in short is related to the edge (perimeter) and area. Therefore, proportion and the mean edge are the most important implications of the clusters and the PCs.

Riitters et al. (1995), Cain et al. (1997), and Cushman et al. (2008) have conducted factor analysis to reduce the numbers of landscape metrics or pattern indicies. The results of our factor analysis have a similar or the same finding as their results, but the factors in our study load on a different axis. For instance, our first factor is similar to the first factor of Riitters et al. (1995) or the sixth factor of Cushman et al. (2008). The remaining factors of our study are similar to the second factor of Riitters et al. (1995) and the 9th, 10th, and 13th factor of Cushman et al. (2008). This loading difference is due to the fact that we targeted our selection at the indication of LST and urban planning. Therefore, landscape-level metrics and many other senseless metrics were not analyzed in our study.

\subsection{Explanation of metrics for identifying LST}

In general, the composition metrics are more important in identifying the LST than the configuration metrics. This is consistent with some previous studies (Zhou et al., 2011; Li et al., 2012; Connors et al., 2013). These studies have tried to investigate the effects of landscape configuration on surface UHI or LST, but have resulted in quantitative statements with some specific configuration metrics, but not configuration in all. Zhou et al. (2011) have stated that "configuration also matters" and explained the statements with each specific configuration metric, such as large patch index (LPI) and patch density (PD). Li et al. (2012) concluded that configuration of green spaces can "significantly decrease LST" also by examining the specific metrics including LSI and ED. Connors et al. (2013) has derived a detailed model for each land use types with the composition and some configuration metrics of the land covers, and found that the effects of configuration were inconsistent among different land uses.

Our results, derived by using a series of stepwise regression and regressions by entering hand-selected variables from all the class-level metrics, showed explicitly that combinations of a composition and a configuration metric could explain more than $66 \%$ of the LST. In detail, PLAND of impervious surface is thought to be the main cause of surface UHI, and explained about $56 \%$ of the LST. Adding one or more configuration metrics such as the mean landscape shape index (LSI) could add another 6-12\% to the explanation.

Our results also resulted in several effective metrics. In detail, LSI and GYRATE_MN are considered to be the most effective class-level configuration metrics for identifying the UHI. They are better than SHAPE_MN as shape metrics because they are considered to be the adjacencies of patches (McGarigal et al., 2012). PLADJ or CLUMPY as contagion metrics were selected by stepwise regression, but were too complicated to be implemented in urban planning. The third primary component (PC3), made up by CLUMPY and NLSI, was also selected by stepwise regression, and so was considered to be a possible alternative to LSI.

The core area metrics (such as CORE_MN) were always grouped into the composition cluster or factor and was proved to be more important in indicating LST than PLAND. The mean core area (CORE_MN) alone explained more than 64\% of the LST. It was better than PLAND alone, because CORE_MN was closely correlated to PLAND with an edge effect considered (Pearson $R=0.783$, correlation analysis results were not shown in the results due to limits on text length). This also indicated that the edge effect on the LST of IS may exist. CORE_MN alone of IS was suggested as the most representative metric for indicating LST. Edge or density metrics such as LSI, NLSI, and GYRATE_MN as configuration metrics were also effective when combined with PLAND.

The determination coefficients also indicated that it is unnecessary to include as many metrics or PCs into the regression models as possible, because adjusted $R^{2}$ vibrated only a little $(<2 \%)$ in different independent variables scenarios (Tables 4 and 5). PCs are especially unnecessary and do not significantly improve the regression fitting performance. However, they make the metrics more difficult to implement and interpret.

\subsection{Implications for landscape metrics selection and urban planning}

Our study suggested that landscape metrics selection should be based on specific processes or specific study areas. For Asian metropolitan Beijing, the PLAND of the impervious surface as landscape composition, and CORE_MN, which was also considered as landscape composition, and three edge related metrics (LSI, NLSI, and GYRATE_MN) were suggested as predictors of the LST. Other 
structural metrics were considered have less value in indicating LST. It was suggested that the PCA was unnecessary. The combination of a composition metric and a configuration metric (chosen based on application purpose) was helpful and easy for LST/UHI indication.

In terms of UHI mitigation and scientific urban planning, emphasis should be placed on decreasing impervious surface proportions or increasing cool land cover such as vegetation and water as much as possible. As the PCA and regression results showed that the percentage of IS in the whole landscape (PLAND) explained more than $56 \%$ of the LST, greening measures such as wall and roof greening could assist UHI mitigation and could be carried out when possible. The results also showed that adding a configuration makes small but useful changes to the results (another $6-12 \%$ for the determination coefficient).

Therefore, the edge or shape design of urban green spaces also has a slight benefit if no available land can be turned into vegetation. As our results showed that integrating landscape shape index (LSI) with composition might explain more variance of the LST than the other configuration metrics combined with the composition, we took LSI as an example. As the un-standardized coefficient of LSI in the regression model is -1.058 , it means that holding the PLAND constant, one unit of increase in natural logarithm of LSI would lead to 1.058 decrease of the mean LST in a landscape. As defined by McGarigal et al. (2012), LSI "measures the perimeterto-area ratio of the landscape as a whole" and has a value larger or equals to 1 and has no dimension. In other words, an increase of perimeter or increase of patch dispersion of impervious surfaces with the same amount will decrease mean LST of the whole landscape. popular landscape pattern indicators for the parsimony analysis of landscape metrics in indicating UHI, which resulted in several findings. First, with UHI-associated LST indication as the target, composition and edge were the two factors needed to represent all of the metrics for Asian metropolitan Beijing. Second, the PLAND of the impervious surface was the most important metric for LST indication, and a combination of PLAND and edge-related metrics such as CORE_MN, GYRATE_MN was necessary and better for UHI indication. Third, PCA with no targeted ecological or environmental processes was unnecessary.

In summary, this study is concerned with the issue of the global urban climate as urban sustainability becomes an inevitable goal of landscape ecology. The results therefore have implications for UHI mitigation and sustainable urban planning. There is still scope for studies using existing landscape pattern indicators. The development of a new landscape pattern index integrating more aspects of landscape pattern and specific ecological/environmental parameters is desirable.

\section{Acknowledgments}

The authors own great thanks to the anonymous reviewers for their time and comments. The Landsat ETM+ images are in courtesy of the U.S. Geological Survey. The whole work was funded by the Natural Science Foundation of China (41230633) and the Innovation Project of State Key Laboratory of Urban and Regional Ecology of China (SKLURE2008-1-02).

\section{Appendix.}
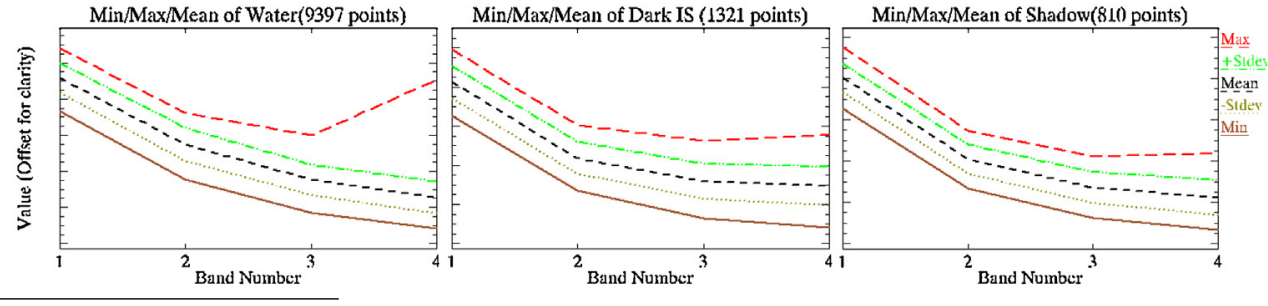

\subsection{Limitations}

Our study is limited in that more specific land cover classes and more scales could be tested beyond the $1 \mathrm{~km} \times 1 \mathrm{~km}$ grid. Additionally, about $30 \%$ of LST was not explained by landscape patterns, for two reasons. First, the anthropogenic heat from buildings and transportation heat as heat from land use also have an effect on LST (Kantzioura et al., 2012), but were not included as we only considered the land cover. Second, simultaneous and adjacent weather conditions could be a factor affecting LST (Schwarz et al., 2012), but has not been included in our analysis.

In general, studies using existing pattern indicators or metrics were similar in that more than one metric was needed, and did not include parameters directly related to ecological processes. An integrated landscape index is therefore required. New integrated indices are needed to integrate not only the composition and configuration of landscape patterns, but also the geophysical parameters that are related mechanically to ecological/environmental processes.

\section{Conclusions}

It is critical to select several useful and representative metrics to indicate a specific ecological process. This study used the most
Appendix B. Supplementary data

Supplementary data associated with this article can be found, in the online version, at http://dx.doi.org/10.1016/j.ecolind. 2014.05.002. These data include Google maps of the most important areas described in this article.

\section{References}

Baker, W.L., Cai, Y., 1992. The r.le programs for multiscale analysis of landscape structure using the GRASS geographical information system. Landsc. Ecol. 7, 291-302.

Buyantuyev, A., Wu, J., 2010. Urban heat islands and landscape heterogeneity: linking spatiotemporal variations in surface temperatures to land-cover and socioeconomic patterns. Landsc. Ecol. 25, 17-33.

Cain, D.H., Riitters, K., Orvis, K., 1997. A multi-scale analysis of landscape statistics. Landsc. Ecol. 12, 199-212.

Cao, X., Onishi, A., Chen, J., Imura, H., 2010. Quantifying the cool island intensity of urban parks using ASTER and IKONOS data. Landsc. Urban Plan. 96, 224-231.

Chander, G., Groeneveld, D., 2009. Intra-annual NDVI validation of the Landsat 5 TM radiometric calibration. Int. J. Remote Sens. 30, 1621-1628.

Connors, J.P., Galletti, C.S., Chow, W.T., 2013. Landscape configuration and urban heat island effects: assessing the relationship between landscape characteristics and land surface temperature in Phoenix, Arizona. Landsc. Ecol. 28, 271-283.

Cushman, S.A., McGarigal, K., Neel, M.C., 2008. Parsimony in landscape metrics: strength, universality, and consistency. Ecol. Indic. 8, 691-703.

Forman, R., Godron, M., 1986. Landscape Ecology. Wiley, Chichester, New York, pp. 619.

Frumkin, H., McMichael, A., 2008. Climate change and public health thinking, communicating, acting. Am. J. Prev. Med. 35, 403-410. 
Gober, P., Brazel, A., Quay, R., Myint, S., Grossman-Clarke, S., Miller, A., Rossi, S., 2010. Using watered landscapes to manipulate urban heat island effects: how much water will it take to cool phoenix? J. Am. Plann. Assoc. 76, 109-121.

Grimm, N.B., Faeth, S.H., Golubiewski, N.E., Redman, C.L., Wu, J., Bai, X., Briggs, J.M., 2008. Global change and the ecology of cities. Science 319, 756.

Ji, C., Liu, W., Xuan, C., 2006. Impact of urban growth on the heat island in Beijing. Chin. J. Geophys. 49, 69-77 (in Chinese with English Abstract).

Jiménez-Muñoz, J.C., Sobrino, J., 2003. A generalized single-channel method for retrieving land surface temperature from remote sensing data. J. Geophys. Res. 108, 4688-4695.

Kantzioura, A., Kosmopoulos, P., Zoras, S., 2012. Urban surface temperature and microclimate measurements in Thessaloniki. Energy Build. 44, 63-72.

Kupfer, J.A., 2012. Landscape ecology and biogeography rethinking landscape metrics in a post-FRAGSTATS landscape. Prog. Phys. Geogr. 36, 400-420.

Li, J., Song, C., Cao, L., Zhu, F., Meng, X., Wu, J., 2011. Impacts of landscape structure on surface urban heat islands: a case study of Shanghai, China. Remote Sens. Environ. 115, 3249-3263.

Li, X., Zhou, W., Ouyang, Z., 2013. Relationship between land surface temperature and spatial pattern of greenspace: what are the effects of spatial resolution? Landsc. Urban Plan. 114, 1-8.

Li, X., Zhou, W., Ouyang, Z., Xu, W., Zheng, H., 2012. Spatial pattern of greenspace affects land surface temperature: evidence from the heavily urbanized Beijing metropolitan area, China. Landsc. Ecol. 27, 887-898.

Liu, H., Weng, Q., 2008. Seasonal variations in the relationship between landscape pattern and land surface temperature in Indianapolis, USA. Environ. Monit. Assess. 144, 199-219.

Liu, H., Weng, Q., 2009. Scaling effect on the relationship between landscape pattern and land surface temperature: a case study of Indianapolis, United States. Photogramm. Eng. Remote Sens. 75, 291-304.

McGarigal, K., Cushman, S., Ene, E., 2012. FRAGSTATS v4: Spatial Pattern Analysis Program for Categorical and Continuous Maps. Computer software program produced by the authors at the University of Massachusetts, Amherst.

Miao, S., Chen, F., LeMone, M.A., Tewari, M., Li, Q., Wang, Y., 2009. An observationa and modeling study of characteristics of urban heat island and boundary layer structures in Beijing. J. Appl. Meterol. Clim. 48, 484-501.

NASA, 2000. Landsat 7 Science Data Users Handbook., pp. 101, From http://landsathandbook.gsfc.nasa.gov/ (retrieved 10.06.13).

Riitters, K., O'neill, R., Hunsaker, C., Wickham, J., Yankee, D., Timmins, S., Jones, K. Jackson, B., 1995. A factor analysis of landscape pattern and structure metrics. Landsc. Ecol. 10, 23-39.
Sarrat, C., Lemonsu, A. Masson, V., Guedalia, D., 2006. Impact of urban heat island on regional atmospheric pollution. Atmos. Environ. 40, 17431758 .

Schindler, S., von Wehrden, H., Poirazidis, K., Wrbka, T., Kati, V., 2013. Multiscale performance of landscape metrics as indicators of species richness of plants, insects and vertebrates. Ecol. Indic. 31, 41-48.

Schwarz, N., Lautenbach, S., Seppelt, R., 2011. Exploring indicators for quantifying surface urban heat islands of European cities with MODIS land surface temperatures. Remote Sens. Environ. 115, 3175-3186.

Schwarz, N., Schlink, U., Franck, U., Großmann, K., 2012. Relationship of land surface and air temperatures and its implications for quantifying urban heat island indicators - an application for the city of Leipzig (Germany). Ecol. Indic. 18, 693-704.

Sobrino, J., Jimenez-Munoz, J., Paolini, L., 2004. Land surface temperature retrieval from LANDSAT TM 5. Remote Sens. Environ. 90, 434-440.

Stone, B., 2009. Land use as climate change mitigation. Environ. Sci. Technol. 43, 9052-9056.

Sun, R., Chen, A., Chen, L., Lü, Y., 2012. Cooling effects of wetlands in an urban region: the case of Beijing. Ecol. Indic. 20, 57-64.

Uuemaa, E., Mander, Ü., Marja, R., 2013. Trends in the use of landscape spatial metrics as landscape indicators: a review. Ecol. Indic. 28, 100-106.

Voogt, J.A., 2002. Urban heat island. In: Munn, T., Douglas, I. (Eds.), Encyclopedia of Global Environmental Change, Volume 3, Causes and Consequences of Global Environmental Change. John Wiley \& Sons, Ltd., Chichester pp. 660-666.

Wang, J., Wang, K., Wang, P., 2007. Urban heat (or cool) island over Beijing from MODIS land surface temperature. J. Remote Sens. (Beijing) 11 (3) 330.

Weng, Q., 2009. Thermal infrared remote sensing for urban climate and environmental studies: methods, applications, and trends. ISPRS J. Photogram. Remote Sens. 64, 335-344.

Weng, Q. Liu, H., Lu, D.,2007. Assessing the effects of land use and land cover patterns on thermal conditions using landscape metrics in city of Indianapolis, United States. Urban Ecosyst. 10, 203-219.

Yu, S., Bian, L., Lin, X., 2005. Changes in the spatial scale of Beijing UHI and urban development. Sci. China Ser. D: Earth Sci. 48 (z2), 97-106.

Zhou, W., Huang, G., Cadenasso, M.L., 2011. Does spatial configuration matter? Understanding the effects of land cover pattern on land surface temperature in urban landscapes. Landsc. Urban Plan. 102, 54-63. 